This article is a commentary on a symposium of articles "Beyond the Therapeutic State" in the European Journal of Psychotherapy and Counselling, which appeared with it as a published response, in EJPC, Vol. 17 No 4, (2015) pp 418-428.

\title{
Psychotherapy and its alternatives: commentary on a critique
}

\section{Michael Rustin}

The aim of this symposium of articles ("Beyond the Therapeutic State") is to develop a critique of the dominant psychiatric paradigm for what the symposium defines as mental illness, and to outline alternative psychotherapeutic approaches to mental suffering. It is a coherent and persuasive advocacy of a position of 'critical psychotherapy'. This article reviews its main arguments, and in its second part offers some partially divergent reflections on how issues of mental health discussed in the symposium should be responded to.

The outstanding paper in my view is "Children's mental health: Time to stop using psychiatric diagnosis," by Sami Timimi. This develops a well-sourced critical analysis of the 'medical model' of illness and treatment as this is applied, in what it calls hegemonic psychiatric practice to mental health, in particular to that of children, although most of its arguments apply to adult services as well. Its thesis can be stated in the following way. In the field of physical illness and treatment, there is no doubt that the 'medical model' has been and indeed remains a successful one. Its science is based on fundamental discoveries about the body and its processes, and continues to advance in its scope. We can add to the author's summary that it is often able to connect symptoms (pains, losses of function, weakness) to their causes, in identifiable diseases or organic malfunctions, sometimes with definite causal agents - bacterial or viral infections, fractures, tumours, immune deficiencies, etc. It has developed batteries of 'technologies' - medical interventions - which have been able to respond to both symptoms and their causes. Entire diseases (e.g. smallpox, polio) have been eradicated through immunization, or if they haven't yet been it is only because their known remedies have not yet been comprehensively 
applied. The course of many illnesses can be fairly accurately anticipated, once diagnoses have been made, with predictable success rates for specified treatments.

There are of course many criticisms that can be made of this 'medical model' even as it has been applied to physical health. Medicine is sometimes omnipotently attached to the idea of cure, at the expense of sparing patients avoidable suffering. There is often insufficient regard paid to psycho-social and relational issues bearing on illness and recovery. There are many distortions in expenditure priorities, for example where investment in research on diseases and their remedies does and does not take place. Environmental and social causes play a large part in the differential incidence of illness - life expectancy differs between social classes in the UK by as much as 10 years. But for all the qualifications one can make, the author of this paper is clear that physical medicine, essentially, works.

Quite the opposite is the case, he argues, for the sphere of psychiatry and mental illness. In this field, there is no level of explanation for most 'illnesses' at a more profound level than that of their symptoms. The diagnostic categories used in psychiatry are essentially descriptors, supported by no basic scientific discoveries about the nature or causes of mental illness. 'Unlike the rest of medicine,' he writes, 'which has developed diagnostic systems that build on an aetiological and pathophysiological framework, psychiatric diagnostic manuals such as DSM 5 and ICD-10 have failed to connect diagnostic categories with aetiological processes. Thus, there are no physical tests referred to in either manual that can be used to help establish a diagnosis." The diagnostic categories systemized in the two major diagnostic manuals are little more than changing catalogues of symptoms, to which are often attached pharmacological interventions whose only claim to effectiveness is in symptom reduction. "None of our medications treat a biological abnormality and none have been shown to improve long-term outcomes."

In physical medicine, the discovery of remedies has often led to the reduction in the incidence and severity of illnesses. But in psychiatry, especially child psychiatry which is this paper's main subject, the writer points out that the reverse has in fact been the case. The coincident rise in classified illnesses and medications deemed to treat them suggests both that the availability (and marketability) of the medications has been driving the diagnostic system, and also that the persistence of some 
conditions (such as depression) may for many sufferers be the outcome of long-term dependence on medications. In a telling analysis, the writer points out that some of the NICE recommendations for pharmacological treatments are virtually unsupported by the evidence which NICE cites to justify them.

Like most other papers in this collection, this paper holds that mental illnesses are constructed by means of social and cultural definition. It suggests that there is a 'colonial' model at work, in which western definitions of mental illness are being propagated across the world in part in order to increase the marketing opportunities for the pharmaceutical industry.

The author Sami Timimi has set out a compelling critique, which deserves to be widely read among mental health practitioners. If he is right, the reality is that mental health requires a quite different forms of understanding, and therefore also quite different forms of preventative and remedial intervention, than physical illness. It is to be noted that the author is not anti-rationalist, anti-scientific or anti-technological in general principle, as some contributors to this symposium appear implicitly to be. His interest is in showing where such forms of scientism are actually applicable, and where by contrast they have (so far) failed.

Other papers in the collection complement Timimi's critique. 'The Triumph of American Psychiatry: How It Created the Modern Therapeutic State' by Robert Whitaker describes the development of the psychiatric hospital and psychiatry profession. It chooses as its starting point the earlier humane origin of the asylum in the Quaker institution of the 'retreat' first set up in 1796, in which people with mental difficulties could be given seclusion, time and sympathetic care in which they could recover. This model was later, however, appropriated and radically transformed by the emerging medical sub-profession of psychiatry, with the invention of the custodial mental hospital, as a major institution of the therapeutic state. In the later $19^{\text {th }}$ and early $20^{\text {th }}$ centuries, eugenics had a role in this take-over, with its idea that mental illness had a genetic basis, and could contaminate society unless its sufferers were segregated. In the mid-twentieth century growing public hostility to incarceration and 
harsh treatment in mental hospitals ${ }^{1}$ gave opportunity to psychoanalysts to gain influence for 'the couch' as a preferred therapy, at one point giving them a degree of hegemony in American psychiatry. But then the psychoanalysts (never very influential in British psychiatry) were displaced by another version of 'care in the community', with the emergence of new psychotropic medications as the supposed cure for mental illnesses. Drugs were marketed vigorously, for example as remedies which it was claimed would work "as well as insulin did for diabetes." The outcome has been a situation in which there has been a proliferation of psychiatric diagnoses, few with scientific merit, and of dependence on medication, with $20 \%$ of Americans taking drugs on a daily basis. The author proposes a return to the 'moral therapy' of the Quakers, though without consideration of how far its effectiveness wmight have depend on an earlier context of shared Quaker beliefs and practices.

John Shotter, in his chapter, "Psychiatric diagnoses, 'thought styles', and ex post facto fact fallacies" provides a critique of the philosophical assumptions which he holds underpins modern beliefs about mental illness and its treatments. The argument is based on a critique of the rationalistic Cartesian assumptions of psychological science. It hold that linear causal reasoning, and the idea that the mind consists of nameable entities capable of being identified and manipulated, as it were 'from outside', is false. "Living in two-way, dialogical relations with our surroundings, rather then in monological, one-way causal relations with them,", the writer states, "means that we can no longer treat ourselves as inquiring simply into a world of 'things' already existing in the world around us. We need to see ourselves instead as always acting 'from within' a still-in-process world of flowing streams of intermingling activities affecting us as much, if not more, than we can affect them. In such a world as this, instead of discovering pre-existing things in our inquiries, we continually bring such 'things' into existence." What this practically amounts to is the need to create a context of dialogue with persons suffering from mental distress, in which they can find meaning in their experience, and develop more tenable ways of being with themselves and others. Examples are given of individuals who have indeed been helped by such experiences, which are persuasive as such particular

\footnotetext{
1 The 'decarceration' movement led by Basaglia and other radicals in Italy was exemplary. (Foot 2015). In the United States, Erving Goffman's writing was influential in this development, and in Britain in the 1960s, R.D. Laing's.
} 
instances can often be.

The two subsequent chapters in the collection, "Stories from the extended therapy room', and "From victimhood to sisterhood- A practice based reflexive inquiry in to narrative informed group work with women who have experienced sexual abuse" each provide examples of how therapies can be conducted which are in sympathy with the philosophical approaches of the symposium. The first of these, by Carina Håkinsson, is based on work over 25 years within the Family Care Foundation, founded in $1987 .{ }^{2}$ It seems that this project was developed to provide an alternative to both psychiatric and psychoanalytic approaches to mental illness; it is rather clearer from the chapter what its own approach to mental disturbance is not, than how its practice is actually designed, although a kind of fostering in family settings is described as one exemplary practice. The writer describes the necessity to be deeply open to the experience of the persons whom the 'extended therapy room' is intended to help, and for the need for this to be a work of co-operation between therapists with one another, and with their clients, in which boundaries and distinctions between them remain fluid, unlike in models of practice which assign expertise to some and ignorance to others. The writer refers to making sense of her years of work in her thesis, and one has the sense that this paper may represent its consolidation in a scholarly form. The chapter gives one confidence in the integrity and deep commitment of the work which is described.

The chapter on narrative work with women, by Leah Salter, is described as part of a doctoral project, but as it appears to have preceded the fieldwork in the thesis it might be thought that it is rather early days to be publishing it. This paper describes the value of shared narratives in enabling women who have been victims of abuse to find space and time to recover from what has happened to them. The work of selfhelp groups, and of narrative therapies, have made valuable contributions.

'Radical Presence: Alternatives to the Therapeutic State' by Sheila MacNamee returns to the Symposium's theoretical argument. It develops a Foucauldian case, drawing also on the writing of Nikolas Rose, against the systems of the human sciences or 'discourses', and their controlling effects in modern life. This is "because no matter what professional domain we

\footnotetext{
${ }^{2}$ The Family Care Foundation is further discussed in the final paper.
} 
encounter, we offer ourselves to the surveillance of experts - expert doctors, expert scholars, expert therapists, expert politicians, xpert managers." These amount to a regulated "therapeutic state" or "psy-complex." The aim of the chapter is to "envision alternatives to popularized, dominant, individualizing, and frequently pathologizing forms of life.....and to explore and imagine alternatives to individualized pathology." The positive argument is for a relational concept of well-being, and for the development of forms of practice which can help to bring this about. The 'psy-complex' of rationalising psychological discourses is assigned the major causal responsibility for bringing about these prevailing individualist mentalities. The author acknowledges that his argument might seem rather vague in its implications for practice, and offers examples to give it specific definition. One example is the Family Care Foundation, previously discussed, whose ethos and ways of working it explains. A second, in an unlikely re-appropriation of behavioural psychologists' interest in rats, describes a project in which isolated rats were freed from addiction to morphine through being returned to their normal social relationships with others of their species. The third describes a community survey in New York City of public attitudes to biological approaches to mental illness. This found strong antipathy to diagnosis and medicalisation, and a preference which was based on "talking to people - therapy, counselling, group therapy being the most common", together with social activities and life style changes "volunteering, hobbies, music, dance, writing, meditation, exercise, yoga, diet, prayer and creating community."

A great deal of weight is placed in this article, and in the whole collection, on adopting a committed, relational approach to mental suffering, and the papers communicate the spirit of this convincingly, in their different ways. The author of the final paper is advocating the development of a 'radical presence', while being careful not to entirely dismiss the whole formal system of mental health care. This idea of creating a 'presence' to exist alongside a 'psy-complex' and a 'therapeutic state' seems however a modest goal, considering how strongly the 'psy-complex' and 'therapeutic state' is being criticised in the symposium.

\section{Commentary}


Interesting and broadly consistent with one another in spirit as these papers are, they bring to mind some critical questions. One of these concerns the analysis of the 'therapeutic state' and 'psy-complex' which underpins much of the argument of the symposium. While the idea of the 'therapeutic state' might seem to assign a great deal of causal responsibility to governments, the arguments of the papers do not support that analysis. In the paper on the development of American psychiatry, the principal agents in the regressive process described are the 'guild' or profession of psychiatry - at one time dominated in the USA by psychoanalysis - and the corporate manufacturers and distributors of drugs. But neither professions nor corporations are mere instruments of the state - indeed psychoanalysis has for most of its history existed in a space distinct from government, and in many societies has been viewed with great suspicion by it. States are best understood as functioning as the mediators and agents of forces, whose social and economic basis lies outside themselves. Imagine for example that the NHS in Britain became largely privatised (now a far from unlikely prospect), and that health care was based, as in the USA, on private medical insurance, albeit of a state-regulated kind. Does anyone imagine that the contraction of the role of the state in such a system would reduce the power of the medical model, or of the pharmaceutical companies, or of the medical profession? The United States experience strongly suggests the exact opposite.

The symposium takes as its starting point, in its opening chapter, the rejection of biological and medicalising models of mental illness, and goes on to recommend broadly 'relational' and ethically focused alternatives to this. What is however absent is a serious consideration of substantial theorizations of the mind and its functions which are not primarily biological or 'medicalised', such as those of attachment theory and psychoanalysis. ${ }^{3}$ Although Freud began his work as a neurologist, and was always interested in the biological substrata of the mind, essentially psychoanalysis, and its part-relative attachment theory, are theories of the mind and its functions, not of the body or the brain, and have become increasingly so as they

\footnotetext{
${ }^{3}$ One could add the unmentioned cognitive behaviour therapy to this list, since it is 'mentalistic' and not biological in its basis, and of course has also been argued for forcefully in the Improved Access to Psychological Therapies (IAPT) programme, in opposition to medication, whatever view one may take of its actual evidence-base and of its antipathy to dynamic psychotherapies.
} 
have developed. Core psychoanalytic concepts such as unconscious mental function, anxiety, repression, splitting, transference, counter-transference, and containment, have proved highly serviceable in understanding what can go wrong in mental life, both during infant and child development and during adult life.

Furthermore they have proved capable of significant development, and of expansion in their scope of explanation. The discovery of the possibility of child analysis by Melanie Klein and her colleagues is one such instance, the elaboration of attachment theory through more conventional experimental methods is another.Indeed one rather suspects that many psychotherapists who disavow any particular commitment the theories of psychoanalysis, in practice find themselves making everyday use of many of its central concepts to make sense of their work with patients.

The contributors to this symposium in effect repudiate the idea that there is any systematic or cumulative body of knowledge of the mind, or of therapeutic techniques, for working with its dysfunctions, which can or should guide therapeutic work. Particularity, complexity and an ethical approach, they imply, is all, without need for theoretical framings. Implicit is a post-modern repudiation of the idea of 'truth' or 'objectivity', a social constructivist emphasis on 'difference' being preferred. (The significant place of Foucauldian perspectives in the symposium marks out its post-modern affinities.) One might say that guiding principles are being looked for in the discourses of philsophy and ethics, rather than those of the sciences, of any variety. Perhaps consistent with this, references to psychoanalysis are few, and those there are are regrettably slighting and superficial. However it does not seem possible to seriously argue that the psychoanalysts' and attachment theorists' attention to early development as a cause of later disturbance has been misplaced, even though it is far from simple to decide how such developmental issues should be engaged with therapeutically.

There is better evidence than the first paper allows for the efficacy of the interventions derived from these 'mentalistic' perspectives. The capacity of attachment models to explain and indeed predict patterns of development, including across generations, has been amply demonstrated. The literature on the outcomes of psychoanalytic psychotherapy with children and adolescents (Kennedy 2004, Kennedy and Midgley 2007, Trowell 2012) also indicates, that these methods 
achieve considerably better outcomes than routine psychiatric treatments. ${ }^{4}$ The fact that these results can be achieved by practitioners from different therapeutic schools does not invalidate their theories, since therapists from different schools of psychoanalysis share many fundamental assumptions. Is it to be doubted that those who have been more deeply trained in psychotherapetic methods, and have learned something substantial about their own 'internal world' in the process, are likely to achieve better results as therapists than practitioners who bring only good intentions to their work?

There are two dimensions of what one might call 'structure' or 'causality' which this symposium has largely avoided. One of these concerns the explanation of mental distress and disturbance in terms of structures of the mind, such as have been evolved by psychoanalysis and by attachment theory with its concept of 'internal working models. The other is the understanding of the social structures which give rise to the individualized, pathologising and regulatory mentalities to which the contributors are rightly antipathetic. The implicit argument of the collection is that it is the 'psy-complex' - that is its ideologies and discourses - which is determinant, and that it is just a matter of human choice to repudiate these discourses and to think and act in different ways. But doesn't it seem likely that significant causal powers also lie elsewhere, in the larger social and economic systems of which the 'psycomplex' is one agent, albeit a significant one. The anxieties of children in schools, students in colleges, individuals dependent on long-term medication to keep going, the scapegoating of minorities and migrants, the depression caused by unemployment and insecurity, the pointless and destructive imprisonment of many deprived and depressed people, are malfunctions of a social system, not merely manifestations of a psy-complex or a 'therapeutic state.' One needs to and work for alternatives to these structures and systems which create stress and disadvantage.

It seems in some ways to be a mis-characterisation of our present state to describe it as a therapeutic state at all. (One remembers John Major's call for us to "'understand a little less".) Indeed, those committed to a relational view of society (Rustin 2014)

\footnotetext{
${ }^{4}$ It is not generally feasible to assess the value of psychotherapies through randomised controlled trials, as it has been many physical medicines, because of the many variabilities that are involved. But this is not to say that on an exemplary basis this should not be done from time to time, as it has been.
} 
might wish for the state to become more and not less therapeutic than it has now become. Where are the resources and commitments to come from to provide the more sympathetic, non-stigmatising and non-judgemental care that those suffering from psychosocial problems are rightly thought by the contributors to need? Are the substantial professions of teachers, nurses, doctors, social workers, and indeed psychologists and psychotherapists, who generally have more sympathetic approaches to these issues than those in many other occupations, to be simply excluded from the idea of care, because they work for, or are regulated by, the 'therapeutic state'? Are the struggles in which many who work in these fields are engaged, to defend human-responsive forms of care against worsening kinds of instrumental and short-termist pressures, to be merely dismissed? What theory of social and political agency do the editors and authors of this symposium have in mind, when they call for alternatives to psychiatric models? Isn't it necessary for those involved in this work to see themselves not as against the state (thus against the role of government as such) but rather as working, as a radical group of social scientists once put it, 'both in and against the state'? (London Edinburgh Return Group 1980). That is, to defend, in the agencies of government as well as in other settings, approaches which are respectful of people and their needs, and which do not adopt irrelevant and often harmful kinds of medicalised remedies for psychosocial conditions.

Psychotherapies of the counter-culture, and a 'radical presence', are not, by themselves, enough, to respond to the situation which this symposium identifies, which is often one of great pain and distress, however the 'psy-complex' may choose to label it.

\section{References.}

Foot, J. (2015) The Man Who Closed the Asylums: Franco Basaglia and the Revolution in Mental Health Care. London: Verso.

Kennedy, E. (2004) Child and Adolescent Psychotherapy: a Systemic Review of Approaches. London: North Central London Strategic Health Authority. http://www.efpp.org/research/systematic review.pdf.

Kennedy, E. and Midgley, N. (2007) Process and Outcome Research in Child, 
Adolescent and Parent-Infant Psychotherapy: A Thematic Review. London: North Central London Strategic Health Authority.

http://www.efpp.org/research/Process\%20and\%200utcome.pdf

London Edinburgh Weekend Return Group (1980) In and Against the State. :London: Pluto Press.

Rustin, M.J. (2014) A Relational Society. In S. Hall, D. Massey and M. Rustin (eds) After Neoliberalism: the Kilburn Manifesto, London: Lawrence and Wishart. Also at http://www.lwbooks.co.uk/journals/soundings/pdfs/Soundings\%20Manifesto Rustin.p $\underline{\mathrm{df}}$

Trowell, J. (ed) (2012) Childhood Depression: a Place for Psychotherapy. London: Karnac. 